\title{
EFFICACY AND SENSITIVITY OF PRENATAL AND POSTNATAL ULTRASOUND SCREENING OF CONGENITAL DEVELOPMENTAL ANOMALIES OF KIDNEYS IN SLOVAKIA
}

DOI: 10.36740/WLek202103112

\author{
Oleksandr Ye. Dobrovanov ${ }^{1,2}$ \\ 'SLOVAK MEDICAL UNIVERSITY, BRATISLAVA, SLOVAKIA \\ ${ }^{2}$ A. GETLIK CLINIC FOR CHILDREN AND ADOLESCENTS, SLOVAK MEDICAL UNIVERSITY AND UNIVERSITY HOSPITAL OF MEDICINE, BRATISLAVA, \\ SLOVAKIA
}

\begin{abstract}
The aim: To compare the effectiveness and sensitivity of prenatal and postnatal diagnostics in the diagnosis of congenital malformations of the urinary system in the Slovak Republic. Materials and methods: Data of postnatal sonographic screening of congenital developmental malformations of the urinary system in Slovak Republic including 2017 were identified and updated using a questionnaire survey, 38,496 newborns were involved. Statistical data on the proportion of prenatal diagnosis for the years 1995, 2000, 2005, 2008 and 2013-2016 were provided from the National Register of Congenital Defects. The chi2-test and t-test were applied to assess the sensitivity differences.

Results: The study showed a low sensitivity of prenatal diagnosis with its maximum in 2016, reaching 32.3\% and a minimum in 2005-2008 (8.0 - 8.4\%). The sensitivity of postnatal diagnostics for selected years has always been a stable indicator and reaches $99.6 \%$.

Conclusions: Available statistical data confirm that prenatal diagnostics of congenital developmental malformations of the urinary system in the Slovak Republic is not perfect. Our work underlines the importance, or we should rather say inevitability of postnatal ultrasound screening for congenital developmental anomalies in the kidneys.
\end{abstract}

KEY WORDS: kidney, postnatal diagnosis, prenatal diagnosis, screening, Slovak Republic, sonography

Wiad Lek. 2021;74(3 p.l):450-454

\section{INTRODUCTION}

Congenital developmental anomalies of the urinary tract (CDAUTs) occur in 1-3\% of all pregnancies and are diagnosed by prenatal and postnatal diagnostic ultrasound. The purpose of the diagnostic ultrasound is to identify the pathology before the onset of severe complications, such as urinary tract infection, formation of renal stones, renal dysfunction of insufficiency. In many cases, the ultrasound detection of uropoetic system dilation is a transient of physiological phenomenon with no clinical significance. However, in some cases the pathology presents serious and life-threatening conditions, such as posterior urethral valves and other types of obstructive uropathy. Such conditions have a significant morbidity and even mortality rates. In many cases, the etiology of uropoetic system dilation cannot be determined prior to birth and requires postnatal diagnostics using various types of imaging exams. In some developed countries, urinary tract dilations are preferably identified as part of prenatal diagnostics due high level of such diagnostics. In Slovakia, newborn screening takes the form of a well elaborated, country-wide preventive programme. With this programme, all monitored diseases are mostly captured in asymptomatic stage which improves the prognosis and quality of life of affected persons. Postnatal ultrasound kidney screening in newborns in the Slovak Republic is a recommended, but for now not mandatory exam. However, it is performed on a country-wide basis $[1,2,3]$. Severe congenital developmental abnormalities of the uropoetic system in Slovakia, requiring the care of a nephrologist and urologist and often urologic intervention in infants affect approximately 3.1-3.9/1,000 infants [1,4]. More marked regional differences have been recorded, namely between eastern and western part of Slovakia. While the incidence in the Preshov Region was 5.3/1,000 live-born infants, in the Bratislava Region it was $2.4 / 1,000$ live-born infants which is a 2.2 -fold difference [4].

\section{THE AIM}

The aim of our effort was to compare the effectiveness and sensitivity of prenatal and postnatal diagnostics in the diagnosis of congenital malformations of the urinary system in the Slovak Republic over the last decades, to underline the importance of postnatal sonographic screening.

\section{MATERIALS AND METHODS}

We have compared the sensitivity of prenatal and postnatal ultrasound diagnostics of congenital developmental anomalies of the uropoetic system in selected years in Slovakia. In cooperation with the National Health Information Center 
Table I. Comparison of sensitivity of prenatal and postnatal diagnostics of CDAUTs in the kidneys in newborns in $2016(\mathrm{~N}=223)$.

\begin{tabular}{|c|c|c|c|c|}
\hline \multirow{2}{*}{\multicolumn{2}{|c|}{$\begin{array}{l}\text { Successful diagnosis of CDAUTs in the kidneys in } \\
\text { the prenatal period in } 2016\end{array}$}} & \multicolumn{2}{|c|}{ Screening } & \multirow{2}{*}{ Total } \\
\hline & & Prenatal & Postnatal & \\
\hline \multirow{4}{*}{ No } & $\mathrm{N}_{\mathrm{p}}$ & 151 & 1 & 152 \\
\hline & $\mathrm{N}_{\mathrm{O}}$ & 76,0 & 76,0 & 152,0 \\
\hline & $\mathrm{N}_{\mathrm{Pr}}$ & $67,7 \%$ & $0,4 \%$ & $34,1 \%$ \\
\hline & SR & 8,6 & $-8,6$ & \\
\hline \multirow{4}{*}{ Yes } & $\mathrm{N}_{\mathrm{p}}$ & 72 & 222 & 294 \\
\hline & $\mathrm{N}_{\mathrm{O}}$ & 147,0 & 147,0 & 294,0 \\
\hline & $\mathrm{N}_{\mathrm{Pr}}$ & $32,3 \%$ & $99,6 \%$ & $65,9 \%$ \\
\hline & SR & $-6,2$ & 6,2 & \\
\hline \multirow{5}{*}{ Total } & $\mathrm{N}_{\mathrm{p}}$ & 223 & 223 & 446 \\
\hline & $\mathrm{N}_{\mathrm{O}}$ & 223,0 & 223,0 & 446,0 \\
\hline & $\mathrm{N}_{\mathrm{Pr}}$ & $100,0 \%$ & $100,0 \%$ & $100,0 \%$ \\
\hline & & \multicolumn{2}{|c|}{$X^{2}(1)=224,557$} & \\
\hline & & \multicolumn{2}{|c|}{$\mathrm{p}<0,001$} & \\
\hline & & \multicolumn{2}{|c|}{$\mathrm{Phi}=0,710$} & \\
\hline
\end{tabular}

Note: NP - frequency observed, NO - frequency expected, NPr - relative frequency observed, $X^{2}$ - chi-square test of independence, $S R$ - standardized residuals, Phi - indicator of the potency of association between observed variables, $p$ - level of significance, $1.96 \leq \mathrm{SR}<2.58(\mathrm{p}<0.05) ; 2.58 \leq \mathrm{SR}<3.29(\mathrm{p}<0.01), \mathrm{SR}>3.29(\mathrm{p}<0.001)$

Source: Author's own elaboration

Table II. Comparison of sensitivity of prenatal and postnatal diagnostics of CDAUTs in the kidneys in newborns in 1995 to 2016 (N=909).

\begin{tabular}{|c|c|c|c|c|}
\hline \multirow{2}{*}{\multicolumn{2}{|c|}{$\begin{array}{l}\text { Successful diagnosis of CDAUTs in the kidneys in } \\
\text { the prenatal period in } 1995-2016\end{array}$}} & \multicolumn{2}{|c|}{ Screening } & \multirow{2}{*}{ Total } \\
\hline & & Prenatal & Prenatal & \\
\hline \multirow{4}{*}{ No } & $\mathrm{N}_{\mathrm{p}}$ & 754 & 4 & 758 \\
\hline & $\mathrm{N}_{\mathrm{O}}$ & 379,0 & 379,0 & 758,0 \\
\hline & $\mathrm{N}_{\mathrm{Pr}}$ & $82,9 \%$ & $0,4 \%$ & $41,7 \%$ \\
\hline & SR & 19,3 & $-19,3$ & \\
\hline \multirow{4}{*}{ Yes } & $\mathrm{N}_{\mathrm{p}}$ & 155 & 905 & 1060 \\
\hline & $\mathrm{N}_{\mathrm{O}}$ & 530,0 & 530,0 & 1060,0 \\
\hline & $\mathrm{N}_{\mathrm{Pr}}$ & $17,1 \%$ & $99,6 \%$ & $58,3 \%$ \\
\hline & SR & $-16,3$ & 16,3 & \\
\hline \multirow{5}{*}{ Total } & $\mathrm{N}_{\mathrm{p}}$ & 909 & 909 & 1818 \\
\hline & $\mathrm{N}_{\mathrm{O}}$ & 909,0 & 909,0 & 1818,0 \\
\hline & $\mathrm{N}_{\mathrm{Pr}}$ & $100,0 \%$ & $100,0 \%$ & $100,0 \%$ \\
\hline & & \multicolumn{2}{|c|}{$X^{2}(1)=1272,745$} & \\
\hline & & \multicolumn{2}{|c|}{$\mathrm{p}<0,001$} & \\
\hline
\end{tabular}

Note: NP - frequency observed, NO - frequency expected, NPr - relative frequency observed, $x^{2}$ - chi-square test of independence, $S R$ - standardized residuals, Phi - indicator of the potency of association between observed variables, $\mathrm{p}$ - level of significance, $1.96 \leq S R<2.58(p<0.05) ; 2.58 \leq S R<3.29(p<0.01), S R>3.29(p<0.001)$

Source: Author's own elaboration

(NHIC), we have identified statistical data regarding the role that prenatal diagnostics played in the diagnostics of congenital developmental anomalies of the urinary tract in 1995, 2000, 2005, 2008 and 2013-2016. Data regarding the selected years have been selected and provided by the National Registry of Congenital Anomalies [5,6]. Data on postnatal screening have been collected using questionnaires that focused on the year 2017. The research involved 38,496 newborns which represents $66.5 \%$ of the entire population of 57,969 babies born in 2017. For the purpose of statistical analysis and processing of collected data we have used SPSS for Windows, version 21.0. On 
Table III. Comparison of sensitivity of prenatal diagnostics of CDAUTs in the kidneys in newborns in 1995, 2000, 2005, 2008 and 2016 (N=155).

\begin{tabular}{|c|c|c|c|c|}
\hline \multicolumn{2}{|c|}{ Year } & \multicolumn{2}{|c|}{$\begin{array}{l}\text { Successful diagnosis of CDAUTs in the kidneys in the } \\
\text { prenatal period }\end{array}$} & \multirow[t]{2}{*}{ Total } \\
\hline & & Yes & No & \\
\hline \multirow{4}{*}{1995} & $\mathrm{~N}_{\mathrm{p}}$ & 91 & 14 & 105 \\
\hline & $\mathrm{N}_{\mathrm{O}}$ & 87,1 & 17,9 & 105,0 \\
\hline & $\mathrm{N}_{\mathrm{Pr}}$ & $86,7 \%$ & $13,3 \%$ & $100,0 \%$ \\
\hline & SR & 0,4 & $-0,9$ & \\
\hline \multirow{4}{*}{2000} & $N_{p}$ & 133 & 35 & 168 \\
\hline & $\mathrm{N}_{\mathrm{O}}$ & 139,4 & 28,6 & 168,0 \\
\hline & $\mathrm{N}_{\mathrm{Pr}}$ & $79,2 \%$ & $20,8 \%$ & $100,0 \%$ \\
\hline & SR & $-0,5$ & 1,2 & \\
\hline \multirow{4}{*}{2005} & $\mathrm{~N}_{\mathrm{p}}$ & 172 & 15 & 187 \\
\hline & $\mathrm{N}_{\mathrm{O}}$ & 155,1 & 31,9 & 187,0 \\
\hline & $\mathrm{N}_{\mathrm{Pr}}$ & $92,0 \%$ & $8,0 \%$ & $100,0 \%$ \\
\hline & SR & 1,4 & $-3,0$ & \\
\hline \multirow{4}{*}{2008} & $\mathrm{~N}_{\mathrm{p}}$ & 207 & 19 & 226 \\
\hline & $\mathrm{N}_{\mathrm{O}}$ & 187,5 & 38,5 & 226,0 \\
\hline & $\mathrm{N}_{\mathrm{Pr}}$ & $91,6 \%$ & $8,4 \%$ & $100,0 \%$ \\
\hline & SR & 1,4 & $-3,1$ & \\
\hline \multirow{4}{*}{2016} & $N_{p}$ & 151 & 72 & 223 \\
\hline & $\mathrm{N}_{\mathrm{O}}$ & 185,0 & 38,0 & 223,0 \\
\hline & $\mathrm{N}_{\mathrm{Pr}}$ & $67,7 \%$ & $32,3 \%$ & $100,0 \%$ \\
\hline & SR & $-2,5$ & 5,5 & \\
\hline \multirow{3}{*}{ Total } & $\mathrm{N}_{\mathrm{p}}$ & 754 & 155 & 909 \\
\hline & $\mathrm{N}_{\mathrm{O}}$ & 754,0 & 155,0 & 909,0 \\
\hline & $\mathrm{N}_{\mathrm{Pr}}$ & $82,9 \%$ & $17,1 \%$ & $100,0 \%$ \\
\hline \multicolumn{5}{|c|}{$X^{2}(4)=62,043$} \\
\hline \multicolumn{5}{|c|}{$p<0,001$} \\
\hline
\end{tabular}

Note: $\mathrm{NP}$ - frequency observed, $\mathrm{NO}$ - frequency expected, $\mathrm{NPr}$ - relative frequency observed, $\mathrm{X}^{2}$ - chi-square test of independence, $S R$ - standardized residuals, (ramer $V$ - indicator of the potency of association between observed variables, $p$ - level of significance, $1.96 \leq S R<2.58(p<0.05) ; 2.58 \leq S R<3.29(p<0.01), S R>3.29(p<0.001)$

Source: Author's own elaboration

the level of statistical description, the collected data have been analysed using numbers $(\mathrm{N})$, arithmetic mean (AM), standard deviation (SD), standard error of estimate (SE), median (Mdn), modus, selection variance, skewness and kurtosis coefficient and minimum and maximum values. Chi2-test and t-test have been used to assess differences in sensitivity of prenatal and postnatal diagnostic ultrasound.

\section{RESULTS}

Results of the analysis show that in 2016 there was a statistically significant difference of $\chi^{2}(1)=224.557, \mathrm{p}<0.001$ between the sensitivity of prenatal and postnatal screening of CDAUTs in the kidneys. To put it more precisely, we have found out that the postnatal screening of CDAUTs in the kidneys showed a significantly higher sensitivity compared to the prenatal screening, $\mathrm{SR}=6.2, \mathrm{p}<0.001$. Prenatal screening only detected $32.3 \%$ of CDAUTs in the kidneys, while with the postnatal screening it was possible to diagnose CDAUTs in the kidneys in as many as $99.6 \%$ cases. Results were not only statistically significant, but had a high level of objective significance $(\mathrm{Phi}=0.710)$, see. table I.

Results of the analysis for the years 1995 to 2016 show that there is a statistically significant difference of $\chi^{2}(1)=1272.745, p<0.001$ between the sensitivity of prenatal and postnatal screening of CDAUTs in the kidneys. To put it more precisely, we have found out that the postnatal screening of CDAUTs in the kidneys showed a significantly higher sensitivity compared to the prenatal screening, $\mathrm{SR}=$ $16.3, p<0.001$. Prenatal screening only detected $17.1 \%$ of CDAUTs in the kidneys, while with the postnatal screening 


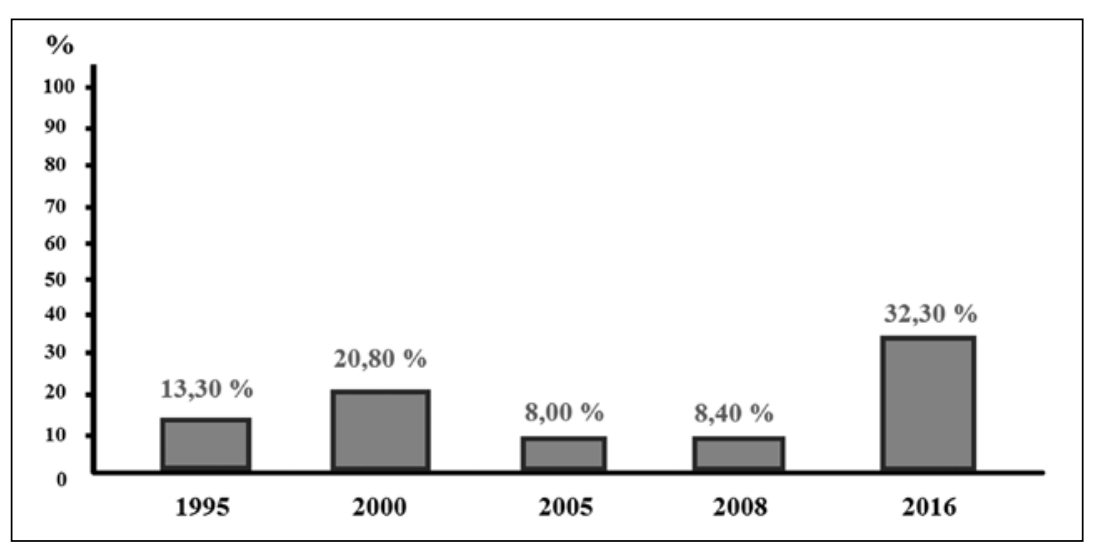

Fig 1. Comparison of sensitivity of prenatal diagnostics of CDAUTs in the kidneys in newborns in 1995, 2000, 2005, 2008 and $2016(N=155)$.

Source: Author's own elaboration and illustration it was possible to diagnose CDAUTs in the kidneys in as many as $99.6 \%$ cases. Results were not only statistically significant, but had a high level of objective significance $(\mathrm{Phi}=0.837)$, see. table II.

To obtain a more comprehensive view of the issue, we have also statistically analysed the differences in the sensitivity of prenatal screening of CDAUTs in the kidneys in newborns in 1995, 2000, 2005, 2008 and 2016. For this purpose, we have conducted the chi-square test of independence which was followed by the analysis of standardized residuals. This allowed us to compare the percentages of newborns with CDAUTs in the kidneys who in the specified years had their condition diagnosed as early as in the prenatal screening.

Results of the analysis showed that there are statistically significant differences in the sensitivity of prenatal screening of CDAUTs in the kidneys in the newborns conducted in 1995, 2000, 2005, 2008 and 2016, $\chi^{2}(4)=62.043, p<$ 0.001 . To be more precise, we have found out that the highest number of CDAUTs in the kidneys was diagnosed in the prenatal screening in 2016, $\mathrm{SR}=5.5, \mathrm{p}<0.001$, when as many as $32.3 \%$ cases of such conditions were captured. On the contrary, the lowest number of CDAUTs in the kidneys was diagnosed in the prenatal screening in 2005, $\mathrm{SR}=-3.0, \mathrm{p}<0.01$ and in $2008, \mathrm{SR}=-3.1, \mathrm{p}<0.01, \mathrm{SR}=5.5$, $\mathrm{p}<0.001$, when only $8 \%$, respectively $8.4 \%$ of cases were captured. Results were not only statistically significant, but also had a nearly moderate level of objective significance (Cramer V $=0.261$ ), see. table III, Fig. 1 .

\section{DISCUSSION}

The first algorithms for the screening for congenital malformations of the kidneys were proposed in 1996 and in 2013 [7]. The author of the screening, docent, M.D. Olga Červeňová, CSc., was awarded the Crystal Wing for the promotion of the nationwide neonatal screening program [3]. The algorithms have been modified and adapted to the current situation with the growing amount of data from practice and statistics.

Ultrasound screening of congenital developmental anomalies in the kidneys in the newborns is the first stage in the diagnostics of serious renal diseases, the treatment of which consequently requires multidisciplinary coop- eration, in particular of paediatricians, nephrologists and urologists [1,2].

With neonatal sonographic screening of the uropoetic system we can detect defects that need to be addressed in the newborn or early infant age. Such anomalies include renal position anomalies, agenesis, dysplasia, obstructive uropathy - dilation of the hollow system according to Hofmann's classification (DHS) and cystic changes. Clinically significant are especially those abnormalities that are associated with impaired urinary outflow - they can lead to recurrent urinary tract infections and subsequently impair kidney function. The vast majority are obstructive uropathies [8].

The current situation in the diagnosis of congenital malformations in Slovakia has not been analyzed for over ten years therefore we carried out a new mapping throughout the territory of Slovakia to underline the importance of the screening for congenital malformations of kidneys, finding problems related to the screening and updating of data.

The proportion of prenatal diagnostics in the diagnosis of congenital urinary system disorders in the Slovak Republic has not yet been analyzed in more detail. We used data from the National Health Information Center to find statistics on the proportion of prenatal diagnostics, which were retrieved and provided from the National Register of Congenital Defects.

The level of prenatal screening in different regions of Slovakia varies to a large extent and there are differences among individual physicians as well [4,9]. Using the data from 2006 we know that prenatally, the suspicion of dilation was only raised in a fifth of all infants $(18.5 \%)[1,3,5]$.

Our study has proven low sensitivity of prenatal diagnostics with maximum numbers achieved in 2016, when it reached $32.3 \%$ (mean: $24.4 \%$ ) a minimum in 2005-2008 $(8.0-8.4 \%)$, pointing to the fact that the sensitivity of postnatal diagnostics in the selected years has always been a stable indicator, reaching $99.6 \%$. This is the very reason why we conduct ultrasound screening for CDAUTs in the kidneys of newborns on a nation-wide scale, with the primary objective to diagnose developmental anomalies which had not been detected prenatally. With the postnatal screening we are able to identify these anomalies with no clinical signs present yet. According to our findings, the structure of hollow system dilations does not differ 
significantly, when compared with the data from 19962006. Serious congenital developmental anomalies of the uropoetic system requiring nephrologic and urologic care and often urologic intervention in early age (in particular significant dilation of the hollow system: stage 3 and 4 of Hofmann's classification) affect approximately 31-39 of 10,000 infants.

Also, to avoid any misunderstanding, it is advisable to include ultrasound screening for congenital developmental anomalies of the kidneys in the group of mandatory screening exams by means of an expert guidance of the Ministry of Health and thus remedy the situation caused by missing legislation. Once again we would like to draw your attention to the fact that in Slovakia, using diagnostic tools, CDAUTs of UPS are only identified in one fourth of infants. Nevertheless, it is a significant step, since it will reveal serious defects which must be dealt with urgently, immediately after birth. At present, the real and biggest advantage of prenatal diagnostics of CDAUTs of UPS in the Slovak Republic is the possibility to ensure early postnatal follow-up and initiate relevant treatment.

\section{CONCLUSIONS}

Available statistical data confirm that prenatal diagnostics of CDAUTs of UPS in the Slovak Republic is not perfect. Our work underlines the importance, or we should rather say inevitability of postnatal ultrasound screening for congenital developmental anomalies in the kidneys.

\section{REFERENCES}

1. Dobrovanov 0., Kralinsky K., Kovalchuk VP., Molcan J. Relevance of ultrasound neonatal screening of the uropoietic system. Ros Vestn Perinatol Pediat. 2019;64(3):68-72. (In Russian).

2. Dobrovanov 0., Kralinsky K., Babela R., Mamrilla R. The importance of screening obstructive uropathy in newborns. Pediatria (Bratisl.). 2018;13(1):17-20.

3. Dobrovanov 0., Kralinsky K., Kovalchuk VP. Ultrasound screening of congenital uropoietic defects and its outlook in Slovakia. Sovremennaya pediatria. 2019; 1(97): 8-12; doi:10.15574/SP.2019.97.8
4. National Center for Health Information (NHIC). http://www.nczisk.sk/ Documents/publikacie/analyticke/vrodene_chyby_2014.pdf.

5. Dobrovanov 0., Kralinsky K. The role of prenatal diagnostics in the identification congenital malformations of urogenital system in Slovakia. Lek. Obzor. 2019;68(2):59-62.

6. National Center for Health Information (NHIC). National congenital malformation register (Slovakia).

7. Červeňová 0.,Payer J.,ZatlukalováA. etal. Algoritmy vyšetrení obštrukčných uropatií v novorodeneckom veku. Slov. Radiol. 1996,3:129-131.

8. Vidiščák M., Huštavová L. a kol. Novorodenecká chirurgia I. M-SERVIS. 2008; $225 \mathrm{p}$.

9. Cisarik F. Current prenatal screening and possibilities of prenatal diagnostics. InVitro (Reprodukčná medicína). 2017;2:28-31.

\section{ORCID and contributorship:}

Oleksandr Ye. Dobrovanov: 0000-0002-9025-9141 A,B,C,D,E,F

\section{Conflict of interest:}

The Author declare no conflict of interest.

\section{CORRESPONDING AUTHOR}

Oleksandr Ye. Dobrovanov

The Hospital of Saint Cyril and Metod

A. Getlik Clinic for Children and Adolescents

Slovak Medical University and University Hospital

3361/11 Antolska st., 85107 Bratislava, Slovakia

tel.: +421949148755

e-mail: brovan.oleksandr@gmail.com

Received: 09.08 .2020

Accepted: 15.12 .2020

A - Work concept and design, B - Data collection and analysis, C - Responsibility for statistical analysis, D-Writing the article, $\mathbf{E}-$ Critical review, $\mathbf{F}$ - Final approval of the article 